\title{
Los cántaros secos. Una revisión de la alfarería tradicional gallega
}

The Dry Pottery. A Review of Traditional Galician Ceramics

Elena Freire Paz

Departamento de Filosofía e Antropoloxía, Universidade de Santiago de Compostela (España)

elena.freire@usc.es

ALFARERÍA POPULAR, LA MEMORIA EN LAS MANOS

MONOGRÁFICO COORDINADO POR ELENA FREIRE PAZ (Universidad de Santiago de Compostela)

\section{RESUMEN}

En este artículo se realiza un análisis antropológico de la alfarería tradicional gallega atendiendo a los cambios socioeconómicos y culturales que han operado sobre este oficio tradicional desde mediados del siglo XX. Topónimos como los de Buño, Oleiros, Gundivós, Niñodaguia, Bonxe o Mondoñedo, entre otros, conforman las cartografías del barro en Galicia. La intervención institucional y política, la renovación de los usos y del valor de los cacharros en una sociedad que ha dejado de ser campesina y se encuentra inmersa en la postmodernidad, así como la continuidad del oficio en determinados puntos de la geografía gallega constituyen los tres ejes que han determinado la supervivencia y puesta en valor de la alfarería tradicional.

\section{ABSTRACT}

This paper outlines an anthropological análisis of traditional Galician pottery taking into account the socio-economic and cultural changes that have operated on this traditional craft since the mid-twentieth centuty. Place names such as Buño, Oleiros, Gundivós, Niñodaguia, Bonxe or Mondoñedo conform the cartographies of clay in Galicia. Institutional and political intervention, the renewal of the uses and value of pottery in a society that has ceased to be peasant and is immersed in post-modernity and the continuity of the craft in certain Galician geographical areas constitute the three axes that have determined the survival and the activation of pottery.

Porque encontraste el tiesto de reserva / en la desolación / descansan a tu lado los siglos de sombra / y te oyen pensar. (Paul Celan)

\section{Introducción}

Muchos son los factores que agravan la dificultad inherente a un intento de condensación y análisis de la situación actual en la que pervive la alfarería tradicional en Galicia, objeto de este trabajo. En primer lugar, la propia definición del sustantivo, que engloba toda producción realizada con materia arcillosa y que, en función de sus distintas características morfológicas y de procesado, puede ser catalogada en tres tipologías diferenciadas (barro, loza o porcelana), nos sitúa ante un escenario difícil de aprehender.

Por otra parte, a esta complicación inicial debemos añadir el hecho de que está sometida a un crecimiento exponencial si atendemos, además, a la amplitud, no siempre diferenciada, que acarrea el adjetivo tradicional (véase Marcos Arévalo 2010). En este caso, no estamos refiriendo solamente cuestiones de fondo como pueden ser la constante revisión o el cribado del pasado que conforman cualquier tradición —lejos de toda percepción sustancialista (García Canclini 1999, Davallon 2014)—y de las que emana ella misma como un producto construido desde el presente y sometido a los procesos de selección propios de la transmisión cultural que son los que terminan por generar a modo de pack "un pasado que se inventa, un presente en construcción y un futuro que se proyecta" (Rivera 2012). Simplemente, enunciamos una mera cuestión de trazabilidad que permita localizar con precisión una determinada producción cultural que hemos elegido objeto de estudio; ¿cuáles son las coordenadas geográficas y temporales de la "alfarería tradicional en Galicia"? 
En este trabajo abordaremos, aunque de forma breve, los caminos por los que ha transitado la producción de cacharros o piezas de barro de basto (Seseña 1997) en diferentes localidades y comarcas de Galicia bajo una perspectiva diacrónica, tomando como referencia las tres etapas (Freire-Paz 2004), claramente establecidas, en la evolución de esta artesanía a lo largo del siglo XX y que presentan continuación en la actualidad. Así pues, habría que puntualizar los tres términos empleados en ese epígrafe: por alfarería entendemos solo la producción en barro basto; con tradicional nos referimos al adjetivo comúnmente empleado para hablar del conjunto de esa producción sin que medie diferenciación cronológica alguna y, cuando la localizamos en Galicia, no nos estamos refiriendo, por supuesto, al conjunto del territorio ni tan siquiera a la totalidad de los centros de producción documentados en un pasado del que todavía se conserva memoria (García Alén 2008).

Consideramos necesario precisar que nuestra intención es orientarnos hacia una perspectiva amplia del tema objeto de análisis, que nos permita una aproximación hermenéutica a la situación de la referida artesanía en atención a sus usos actuales. En este sentido, nos veremos obligados a traspasar el umbral descriptivo y el carácter recopilatorio que ha centrado la mayor parte de las publicaciones que han abordado el estudio de la alfarería en otras latitudes del estado español hasta el momento. Sin entrar en un repaso detallado sobre los trabajos llevados a cabo sobre esta temática en todo el territorio estatal, por una cuestión de racionalidad en lo que se refiere a la extensión de este texto, así como porque no es este el objetivo propuesto, no deja de resultar sorprendente que, aun en las más recientes publicaciones, se mantenga el perfil de monografía dominante en las aproximaciones realizadas ya durante las décadas de 1970 y 1980 bajo las premisas de localizar y rescatar los rescoldos de una actividad inexorablemente abocada a la desaparición y que atesoraban, aún, las directrices de los folkloristas decimonónicos trasladadas al estudio de las sociedades campesinas que agonizaban en Europa. En ellas dos premisas se cumplen casi de forma obligatoria: por una parte, el cuerpo narrativo comienza por relatar las distintas fases del proceso de elaboración desde un punto de vista más o menos técnico, pasando después a centrarse en la enumeración descriptiva de las piezas atendiendo a tamaños, formas y usos. Por la otra, habría que destacar la profusa reproducción de distintos tipos de material visual (fotografías, croquis, esbozos y/o dibujos) que cumplen una función didáctica e ilustrativa de lo expuesto mediante la palabra.

Sobre este mapeo general de los trabajos que, desde la etnografía, se han llevado a cabo sobre alfarerías tradicionales de algún lugar (pueblo, comarca o comunidad autónoma) del panorama español, el caso gallego ofrece una particularidad: la existencia de estudios académicos y publicaciones científicas que enmarcaron el análisis sistemático de la alfarería tradicional en las dinámicas características de las postrimerías del siglo XX y comienzos del XXI. Las razones para entender este factor diferencial serán expuestas a lo largo del presente texto, pero, a modo de avance, debemos decir que fue justo en ese momento cuando un oficio popular, en apariencia inocuo, se convirtió en el hilo simbólico conductor de los tres vectores ideológicos que definen el momento actual: lo económico, lo político y la memoria, entendiendo esta como una "performance del recuerdo" (Bustamante 2019: 9). Y lo hizo, por supuesto, desde unos condicionamientos en los que, como afirma Nieves Herrero: "Podría parecer paradójico hablar de postmodernización en un contexto como (...) Galicia, en el que aún muy recientemente hemos alcanzado los parámetros clave que se han utilizado para definir la modernidad en algunos ámbitos" (Herrero 2011:295). Y, sin embargo, ha sido a nuetsro entender ese contexto sociocultural, cuyas particularidades pasamos a detallar, el que ha determinado la excepcionalidad del caso gallego y su traslación a la categoría de texto en el ámbito académico.

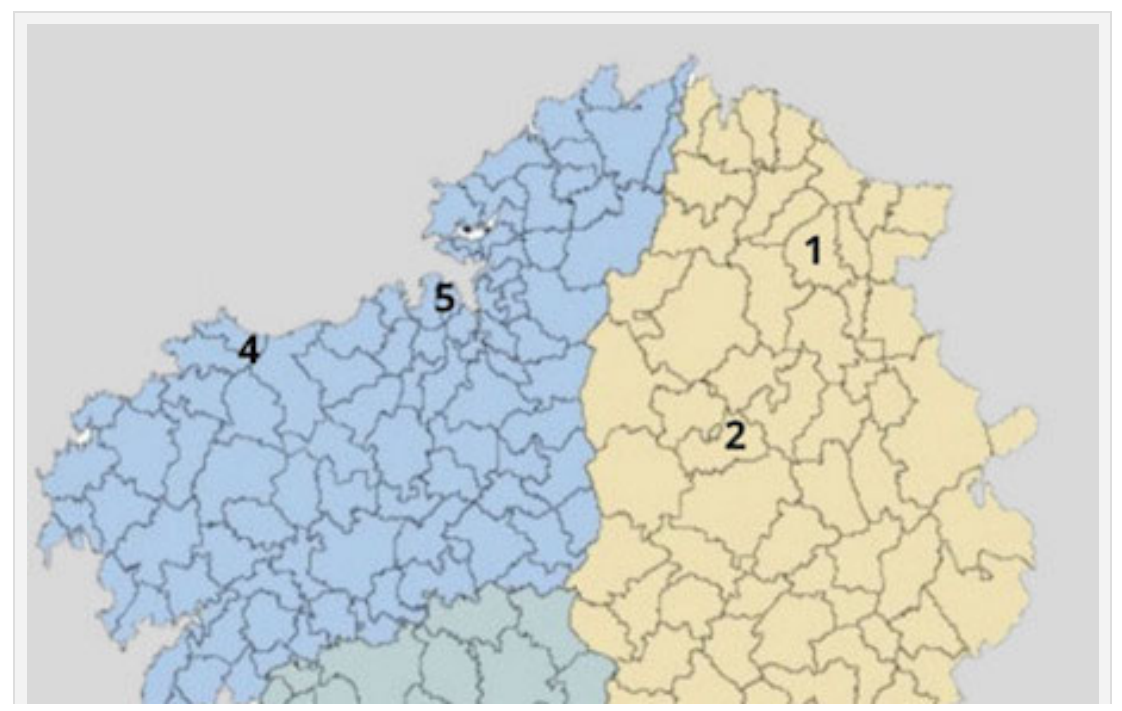




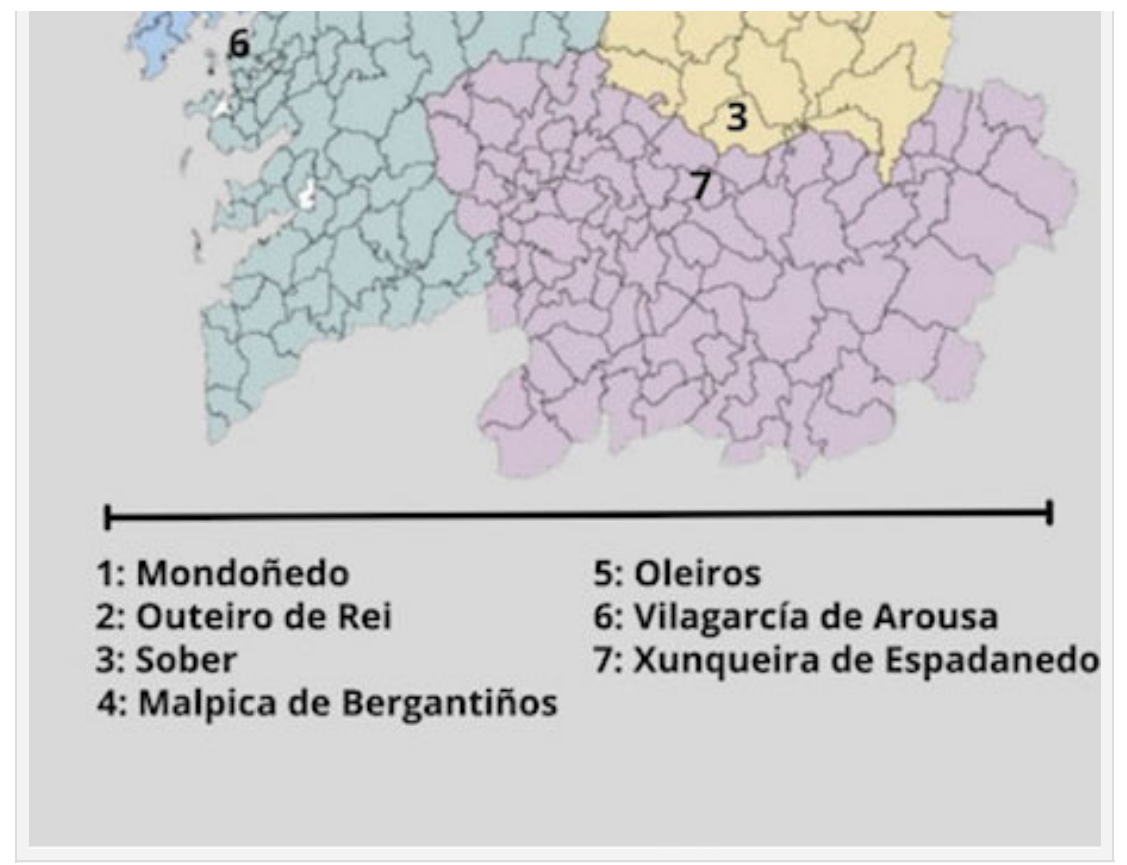

\section{La alfarería tradicional: ¿un oficio del pasado?}

Hoy es posible adquirir piezas de alfarería tradicional elaboradas en talleres diseminados por las cuatro provincias gallegas (a modo de ejemplo y con la finalidad de que el lector conozca los topónimos correspondientes citaremos aquí Buño, Bamio, Portomourisco, Loñoá, Samos, Bonxe, Tioira, Niñodaguia, Mondoñedo y Gundivós, entre otros), siendo una de las artesanías en las que reposa la identidad del noroeste peninsular y que constituye una manifestación más del patrimonio inmaterial. Una categoría en la que el turismo confluye con la artesanía en tanto en cuanto esta forma parte al tiempo que da forma a una cultura viva de la que el mercado demanda en cuotas proporcionales "cultura, experiencia, exotismo, tradición, popular y autenticidad" (Jiménez 2019: 807).

A este binomio entre lugar de producción y de venta habría que añadir, también, otros circuitos habilitados para su distribución, como pueden ser las tiendas de artesanías presentes en lugares más o menos alejados de los polos de producción, más abundantes en villas y ciudades, y, por supuesto, las ferias que pueden tener un carácter generalista, vinculadas a muestras de artesanía y/o productos gastronómicos, o bien especializado monográficamente en el barro. Así, sobre una actividad productiva y comercial contemporánea se vuelca la memoria de un pasado resemantizado en el que, además, confluyen de forma cada vez más imprecisa lo artístico y lo artesanal (Rei 2016). Recordemos que, como afirman Estrada y Mármol (2014: 46):

"La patrimonialización es entonces un proceso que altera el significado de elementos del pasado en un nuevo contexto social y económico, dando lugar a nuevos productos. La naturaleza, el paisaje y la cultura local se han visto así transformados y redefinidos en nuevos universos de sentido. (...) Los oficios quedan (...) incorporados en la dinámica patrimonial”.

Toda vez que el oficio ha pasado a estar englobado en el mundo del patrimonio, las consideraciones sobre él han variado de forma sustancial y las coordenadas del presente han alterado barreras impensables de franquear en las comunidades originarias, como puede ser la diferencia entre la genialidad atribuida al arte y la repetición continuada de una tarea que se insertaba en un modo de producción proto-industrial — de ahí su propia catalogación como oficio-, como decíamos hace un momento, mientras se mantiene sobre una narrativa de recuperación y rehabilitación del pasado. Esta especie de esquizofrenia colectiva, por lo menos a nivel discursivo, es la que sostiene y es sostenida por la alfarería tradicional. Una paradoja que, sin embargo, no debe de resultar llamativa cuando el "régimen patrimonial" (Hafstein 2012) sigue reproduciendo la clásica diferenciación entre "patrimonio de élites o artístico frente a patrimonio popular o folklore" (Quintero y Sánchez-Carretero 2017: 50).

La pervivencia de la alfarería tradicional en la Galicia actual se explica a través, fundamentalmente, de tres caminos. En primer lugar, estarían aquellas zonas en las que, por diferentes razones que explicaremos más adelante, el trabajo del barro se mantuvo sin interrupciones temporales y, por lo tanto, 
ha estado sometido a la totalidad de los cambios económicos, sociales y culturales acaecidos durante los últimos sesenta años, los cuales han producido una alteración constante tanto de los modelos como de los procesos. Sirva como mínimo ejemplo la producción en Buño (A Coruña) de pulseras y broches ornamentales para colaborar, a través de la Asociación Oleira de Buño, con la Asociación Visibles y la Asociación Mirabal centradas en ayudar a las víctimas de la violencia de género y defensa al menor a través de la iniciativa Zoquiñas vermellas.

El segundo de los caminos ha sido trazado a través del uso institucional y político de la alfarería tradicional por parte del Partido Popular para establecer los símbolos de una identidad cultural que reposa dócilmente sobre la ensoñación de una Galicia completamente alejada de lo que en su día pudo ser la violencia en el País Vasco y, por supuesto, de la reivindicación de autonomía catalana. En este sentido, el proceso de recuperación y promoción de la alfarería tradicional gallega auspiciado por la Diputación Provincial de Lugo a finales de los años noventa y principios de los dos mil resulta paradigmático. Como bien indica Juan Agudo (1999: 39), "los 'hechos culturales', en los momentos que anteceden o siguen a los respectivos proyectos autonómicos, se convierten en argumentaciones fundamentales para justificar el nuevo orden político. La cultura se transforma en una justificación de lo político". El interés de esta utilización se superpone, al menos, en tres planos diferenciados.

En primer lugar, estaría la apropiación que, desde la transición, y amparándose en las bases de la dictadura, los partidos políticos situados en el abanico ideológico de las fuerzas conservadoras o de derechas han realizado del folclore (Miramontes 2021) y cómo han hecho acopio de todas aquellas imágenes que eran susceptibles de representar, a nivel simbólico, todo aquello que se desmantelaba a nivel económico y político. En este sentido, ya forman parte de la memoria colectiva las imágenes de las tomas de posesión de Manuel Fraga en la Praza do Obradoiro rodeado de gaiteiros o sus queimadas con Fidel Castro en Cuba, donde el recipiente que ocupa el primer plano funciona como contenedor, no solo del líquido elixir, sino también de la identidad compartida entre hijos de la emigración y, por lo tanto, herederos de ancestros de una "patria" común.

En segundo lugar se encontraría la extrapolación del oficio del barro al terreno económico y social, que las mismas fuerzas llevaron a cabo a través de la artesanía, en general para poder tener acceso a los planes de compensación a fondo perdido tras la entrada en la Unión Europea de España y la ratificación de la Política Agraria Común que suponía, de facto, la práctica desaparición de la actividad productiva más significativa para Galicia, hasta el punto de que esta comunidad autónoma pasó a estar clasificada como Objetivo I, lo que evidenciaba su alta vulnerabilidad en términos económicos al tener que hacer desaparecer, de forma obligatoria, las actividades que soportaban su tejido económico. Esa Galicia campesina que acelera su desaparición, de forma involuntaria, con la entrada en Europa, ha de reconvertirse hacia el sector servicios en un nivel terciario en el que la "recuperación" y el aprovechamiento simbólico de los bienes se torna en capital en circulación; ya fuese en ayudas directas a través de los planes LEADER/PRODER o mediante la apertura de talleres que habilitasen actividades económicas en la zona rural. En este engranaje habría que ubicar, por ejemplo, la producción de cacharros en las localidades de Mondoñedo, Bonxe y Gundivós (Lugo).

En tercera y última posición habría que atender a las luchas internas dentro del Partido Popular, que ha ostentado el gobierno de la autonomía de manera ininterrumpida desde la creación de la Xunta de Galicia en 1981, con las únicas excepciones de los gobiernos tripartito (de septiembre de 1987 a febrero de 1990) y bipartito (de agosto de 2005 a marzo de 2009). Pues bien, la alfarería tradicional pasó a ser un elemento determinante y se convirtió en el terreno de disputa entre los denominados sectores de "la boina" y "el birrete", que se enfrentaron por el poder dentro del mismo organigrama político. Las razones están vinculadas a lo anteriormente expuesto en la primera de nuestras reflexiones: las capacidades de representación y de disponibilidad económica que la elemental materia prima del barro llegó a ostentar en el cambio de milenio.

Por lo que respecta al tercero de los caminos que han traído a la alfarería tradicional gallega hasta nuestros días, cabe apuntar que estaría vinculado con los usos de la memoria y, de forma subsidiaria, con la impronta de la tecnología asociada a las redes sociales. Como bien sabemos, "las identidades y la memoria simplemente no se 'encuentran', 'producen' ni 'reflejan' en los sitios o momentos patrimoniales, sino que son recreadas y negociadas continuamente a medida que las personas, las comunidades y las instituciones reinterpretan, recuerdan, olvidan y reevalúan el significado del pasado en cuanto a las necesidades sociales, culturales y políticas del presente" (Smith 2011: 60). Pues bien, desde el año 1997 la Asociación de Mulleres Rurais de Bamio está llevando a cabo un trabajo de exhumación de la 
memoria. En ese lugar de la provincia de Pontevedra, en el que no se encuentra la materia prima necesaria para la producción alfarera (llegaba por barco), existió, hasta los años cuarenta del siglo XX, un centro de elaboración de cacharros que ha supuesto el hilo conductor del asociacionismo femenino de la zona en pleno siglo XXI gracias a la iniciativa de una arqueóloga (Beatriz Comendador) profesora de la Universidade de Vigo, que promovió dinámicas de intervención participativas en la zona y que, finalmente, han devenido en una comunidad armada alrededor de esta actividad tradicional pero con fuertes imbricaciones en el momento actual. Así, el factor de género vuelve a manifestarse como crucial, como en el caso de Buño, en la encrucijada de un contexto rural claramente subordinado a los emplazamientos urbanos - aunque la zona se corresponda con el Eje Atlántico- y con el apoyo que proporciona el uso de las nuevas tecnologías, y más en concreto el caso de las redes sociales, que permiten una proyección de más largo alcance para la iniciativa y que también favorecen la creación de contactos y la consecución de fuentes que amplíen el proyecto.

El tránsito de la alfarería tradicional gallega por los usos de la memoria, como conector social, desde el presente implica una novedad en el tratamiento del oficio. Este ya no aparece vinculado a la rentabilidad, en términos económicos, de iniciativas particulares (la apertura de nuevos obradores y tiendas que jalonó el cambio de siglo) ni al aprovechamiento político de las imágenes que contenían las piezas de barro o los portadores de saber en los que se convirtieron los alfareros sometidos, al igual que los productos, a los parámetros de una clasificación Unesco. Asistimos pues, en la alfarería gallega tradicional del último lustro a lo que anticipaba Néstor García Canclini (1999: 33) hace más de veinte años:

"Un patrimonio reformulado que considere sus usos sociales (...) con una visión más completa de cómo la sociedad se apropia de su historia, puede involucrar a nuevos sectores. No tiene por qué reducirse a un asunto de los especialistas del pasado: interesa a los funcionarios y profesionales ocupados en construir el presente, a los indígenas, campesinos, migrantes y a todos los sectores cuya identidad suele ser trastocada por los usos hegemónicos de la cultura".

De nuevo, la alfarería tradicional gallega abre otro camino para el futuro insertándose, aunque sea de forma puntual, en la avanzadilla de los procesos sobre el patrimonio a través de la "Innovación abierta" lo que supone la ampliación de los límites del patrimonio en todos los sentidos, entendiendo que la construcción social del conocimiento "no es un fundamento ajeno a la sociedad, se desarrolla dentro de ella, a partir de sus intereses, códigos y sistemas. La innovación, entendida como la efectiva incorporación social del conocimiento en la solución de problemas o en el establecimiento de nuevas relaciones, no es más que la interacción entre grupos, artefactos, culturas sociales de expertos y no expertos" (Carrera 2019: 225).

\section{De aquellos barros, estos lodos}

La llamada alfarería tradicional en Galicia está formada por lo que podríamos denominar dos conjuntos disjuntos pero incardinados en la misma raíz. Por una parte, se encontrarían aquellas piezas de alfarería correspondientes a un momento que denominaremos, en términos históricos, como "etapa antigua", a la que haremos referencia e intentaremos definir y delimitar en una cronología posterior, y que se desarrolla de manera continua desde los orígenes imprecisos de esta artesanía en este territorio hasta aproximadamente la década de 1960. Por otra parte, hace falta destacar que, sin que exista ninguna discontinuidad visual, espacial ni conceptual, y formando, por tanto, un conglomerado unitario en cuanto a su representatividad simbólica y cultural, también recoge piezas procedentes, de nuevo, de distintos puntos geográficos gallegos, pero que se corresponden con un momento productivo diferente, que denominaremos "contemporáneo", ya que coincide con una etapa que arranca aproximadamente en la década de 1990 y llega hasta la actualidad. Entre los dos períodos históricos referidos existió una etapa caracterizada por la decadencia o abandono paulatino de la actividad en la mayor parte de los talleres gallegos y que abarcó, grosso modo, algo más de dos décadas. 


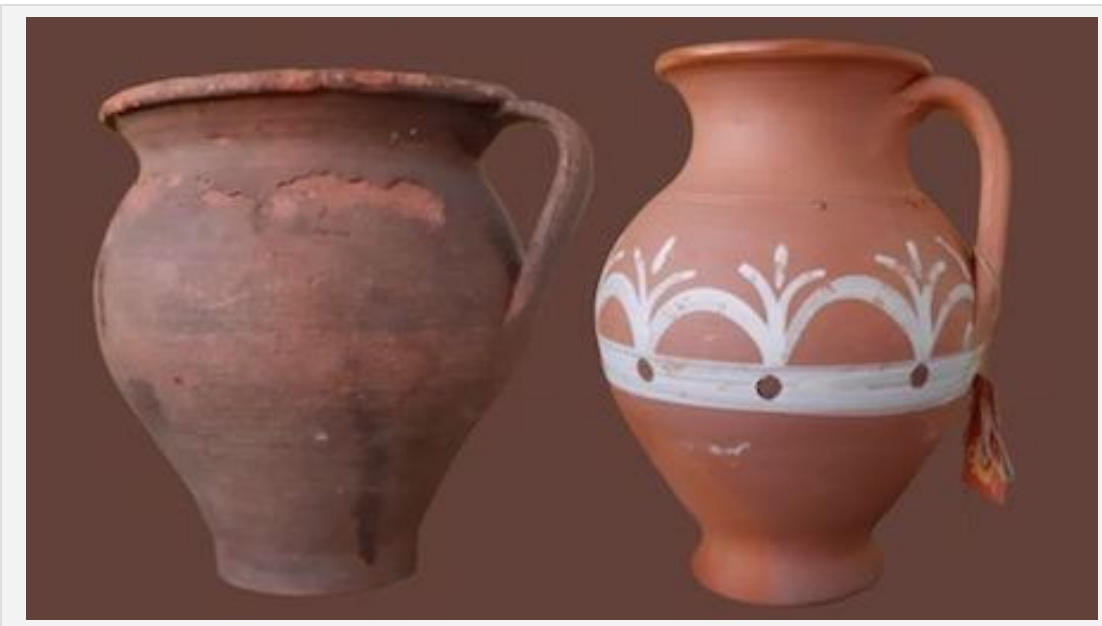

Púcaros elaborados en talleres de la zona norte de la provincia de Lugo antes de 1960 y después de 1990.

Esta etapa intermedia podemos situarla entre los años sesenta y ochenta del pasado siglo, aunque debemos dejar constancia de que este movimiento de regresión de la alfarería galaica no ocurrió de manera sincronizada en todos los centros productivos, sino que se decantó con variaciones internas considerables. Como ejemplo, sirva mencionar la mayor pervivencia del oficio en lugares como Buño y Oleiros, que contaban con numerosos talleres en los que el binomio taller-tienda, o elaboración-venta, funcionó como freno a la crisis de la artesanía en aquellos años, mientras que en otras localizaciones las tareas de producción y distribución estaban menos unificadas, al menos desde un punto de vista espacial, lo que terminó por provocar una disipación más acelerada de la actividad. También hace falta señalar que, curiosamente, en zonas de carácter semiurbano, como Mondoñedo, donde el oficio alfarero pasó a constituir en algunos casos una actividad complementaria de la dedicación principal de los artesanos en las industrias de la comarca, estos mantuvieron el oficio de manera ininterrumpida. Esta mayor pervivencia del oficio, también se constata en aquellos lugares a los que retornaron emigrantes retirados, procedentes, de países europeos, que retomaron la actividad artesanal que habían ejercido en su juventud, u otros que comenzaron su aprendizaje motivados por la conjugación de dos factores principales: por una parte, el hecho de tratarse de personas con una situación económica ya resuelta, puesto que se encontraban jubilados y tenían asegurados unos ingresos, pero que aún eran activos desde el punto de vista laboral y conservaban unas buenas condiciones físicas para el trabajo; por otro, la dedicación a la alfarería tradicional funcionó como una fuente "extra" de ingresos que tampoco exigía una dedicación plena ni intensiva en atención a una demanda discontinua y esporádica, coincidente casi siempre con los períodos vacacionales, y que estaba auspiciada o favorecida por una especie de incipiente "turismo cultural" o, por mejor decir, turismo en torno a determinadas manifestaciones culturales. Así, algunas zonas, como Gundivós, mantuvieron la actividad alfarera con una producción restringida, que abastecía de piezas de barro a un mercado limitado y, hasta cierto punto, determinado por el interés hacia unos objetos representativos de los últimos vestigios de la realidad histórica, social y vital inmediata, ya condenada a irremediable desaparición. Es decir, se trataba de un turismo más vinculado a una posible evocación o reminiscencia exótica y curiosa hacia un mundo en progresiva extinción o ya periclitado que a las características que hoy en día se atribuyen al turismo cultural como respuesta identitaria e ideológicamente consciente y alternativa en la era de la globalización económica y su consecuente homogeneización cultural, coordenadas estas que, como veremos más adelante, sí caracterizan al período actual de mantenimiento de esta actividad tradicional. 


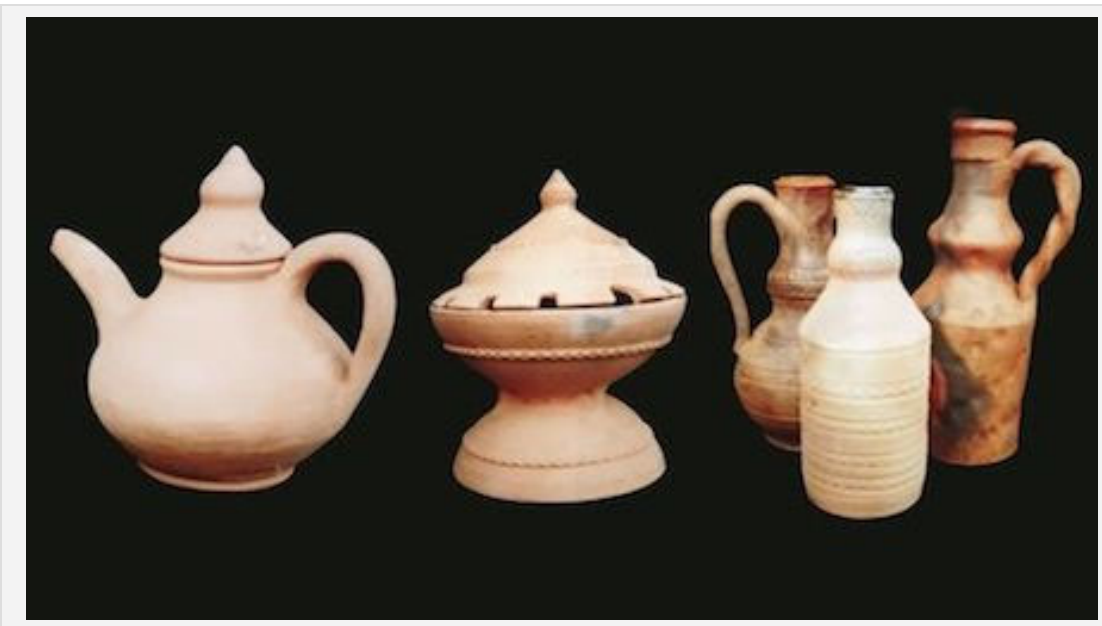

Diferentes piezas elaboradas en Gundivós, año 1999.

Curiosamente, en los casos mencionados la pervivencia del oficio o, cuando menos, su aguante ante la adversidad provocada por la caída de las ventas, no estuvo relacionada con la posibilidad de una consideración social hacia los productores de un oficio relegado en la escala social al sector primario y rural (valores muy preciados ahora mismo pero denostados en aquel momento), sino vinculado con una producción industrial o con una actividad que incluso podemos clasificar cómo lúdica, más allá de la necesidad económica de subsistir cuando las artesanías en general, y dentro de ellas también la alfarería, suponían en el mundo tradicional dedicaciones vinculadas a la actividad económica y su existencia posibilitaba un modo de vida para quien desempeñaba el oficio. En todo caso, resulta innegable que durante ese período de la segunda mitad del siglo XX la alfarería gallega atravesó una etapa de silencio en la que muchos artesanos abandonaron definitivamente el oficio y que supuso la ruptura entre los dos momentos productivos a los que puede pertenecer cualquier pieza catalogada, indistintamente, como alfarería tradicional gallega.

Así pues, a lo largo del siglo XX, la alfarería tradicional gallega atravesó por tres etapas que se definen y explican, fundamentalmente, por la demanda de sus productos. Este hecho, tan pragmático y visiblemente material, parece contrastar con la imagen idealizada que hoy en día proyecta la alfarería y el producto artesano, pero inscribe a una y a otro en una realidad que le fue siempre propia, como es la de tratarse de una fuente de ingresos y, por lo tanto, de un medio de vida. Además, la vertiente económica del oficio artesano tampoco puede ser analizada al margen de otro tipo de factores, de carácter social e incluso cultural, que subyacen en cualquier transacción monetaria y que, sin duda, forman una parte enriquecedora del análisis antropológico sobre el oficio.

Una de las primeras características que es preciso señalar para intentar explicar estos tres momentos diferentes de la producción alfarera tradicional en Galicia es la datación del primer período al que nos hemos referido. Si bien es posible establecer el momento de decadencia de la actividad, el inicio de esa primera fase de producción se pierde en el tiempo; es decir, hablamos de un período indeterminado en su comienzo que permite teñir las piezas -y el oficio- heredadas con una serie de connotaciones semánticas y simbólicas que se encuentran en relación con el tiempo y el espacio del Mito más que con los de la Historia.

Además, el hecho de que la alfarería sea un oficio presente en todas las grandes civilizaciones de la humanidad, en todas las culturas y en todos los continentes, no hace sino marcar esta artesanía con unas connotaciones simbólicas que aúnan elementos muy significativos a la hora de convertirlo en un bien susceptible de ser puesto en valor y que encajan en un tiempo mítico que está, propiamente hablando, fuera del tiempo real, pero que se evoca en la construcción de las identidades para localizar en la indefinición que ofrece la expresión "de siempre" el cronotopo que se pretende crear y proyectar. La tradición que se pierde en el tiempo funciona, así, como un anclaje de lo propio que se revaloriza frente al ajeno percibido como una novedad que no cuenta, por el hecho de ser nueva, con el peso específico que otorga el paso del tiempo.

\section{Lo que éramos y lo que queremos ser: producción y consumo}


Hundiendo sus raíces en esas reminiscencias de un pasado inmemorial, la alfarería tradicional gallega mantuvo a lo largo del tiempo una producción sucesiva, no interrumpida, supuestamente caracterizada por una continuidad invariable de los elementos materiales y formales y del sistema productivo. Las características de ese primer período, que podemos denominar como fundacional o mitológico y, por lo menos a simple vista, invariable, estaban marcadas por una finalidad funcional esencial para los objetos creados con barro, pero también por su reafirmación a través de su carácter permanente, incrementado por la existencia de unas marcadas connotaciones típicas tanto de las personas que las producían como, también, del colectivo formado por los consumidores de estas.

De este modo, por lo que respecta al colectivo de los productores, debemos decir que, durante años, la alfarería gallega fue un oficio tradicional, es decir, transmitido de generación en generación, y desarrollado de manera mayoritaria por artesanos pertenecientes al campesinado, identificando este grupo social de una manera más amplia que la visión, siempre reduccionista, del labriego exclusivamente como agricultor, ya que algunas actividades artesanales o de manufactura tuvieron un papel decisivo para el mantenimiento de población vinculada al campo. Así, como decíamos, durante generaciones los artesanos del barro fueron responsables no solo del traspaso de la herencia cultural que supone la transmisión de los objetos materiales y de los útiles, sino también de los conocimientos necesarios para elaborar las piezas.

Estas caracterizan su identidad en tanto que suponen respuestas adaptativas al lugar y al tiempo en el que se inserta cualquier manifestación cultural bajo un aura de uniformidad que finalizó por otorgarle un carácter compacto que funcionó, con el paso del tiempo, como un marcador de cohesión social. Esta sucesión generacional se vio reforzada por el hecho de que el aprendizaje del oficio se hacía dentro de las propias familias de los alfareros o, en todo caso, los aprendices que no tenían antecedentes directos con el mundo del barro comenzaban su relación con la actividad desde muy jóvenes, en un proceso equiparable al de una adopción precoz del rol social que habían de desempeñar y en la que, cuanta menos edad tuvieran, mayor sería la capacidad de asumir la representatividad del oficio. Así, los alfareros tradicionales comenzaban desde la infancia el oficio, al igual, por cierto, que todos los trabajos propios del campo, y esta temprana vinculación reforzaba su poder de representación como maestros dominadores de la técnica y del conocimiento frente al resto del grupo, independientemente de que fueran hijos o nietos de una o varias generaciones precedentes de alfareros. En este sentido, tal y como afirma Honorio Velasco (2012), "la tradición oral (...) es un proceso sustancial a las artesanías, cuyo aprendizaje suele estar basado en la imitación de los modelos más habilidosos y en la adecuada recepción de los acertados mensajes e informaciones valiosas que pasan de las generaciones mayores a las jóvenes".

Esta faceta de poseedores de un oficio iba unida a la consideración social de los alfareros como campesinos, aunque como campesinos no propietarios de tierras lo suficientemente importantes 0 significativas como para dedicarse al campo en exclusividad; esta circunstancia los situaba, sin lugar a dudas, en un nivel jerárquico social inferior al de los campesinos propietarios, dedicados en exclusiva a la actividad agrícola y/o ganadera (como parece ocurrir, por cierto, en otros casos heterogéneos, como la situación de los alfareros mexicanos estudiados por George M. Foster y referenciados por Lévi-Strauss, que coincidían en considerarse inferiores a los labradores o a los pequeños comerciantes). Pero, por otra parte, y casi como compensación a todo esto, el ejercicio del oficio les reportaba unos ingresos en efectivo que también contribuían a singularizarlos dentro del medio social: su estatus económico tenía carácter simbólico, es decir, monetario, frente a la nada pragmática posesión de la tierra, que no podía ofrecer a los propietarios unos ingresos semejantes ni en cuanto a la cantidad ni en cuanto a la frecuencia. Los alfareros eran, pues, individuos que manejaban ciertas cantidades de dinero en una sociedad caracterizada eminentemente por la carencia de este. 


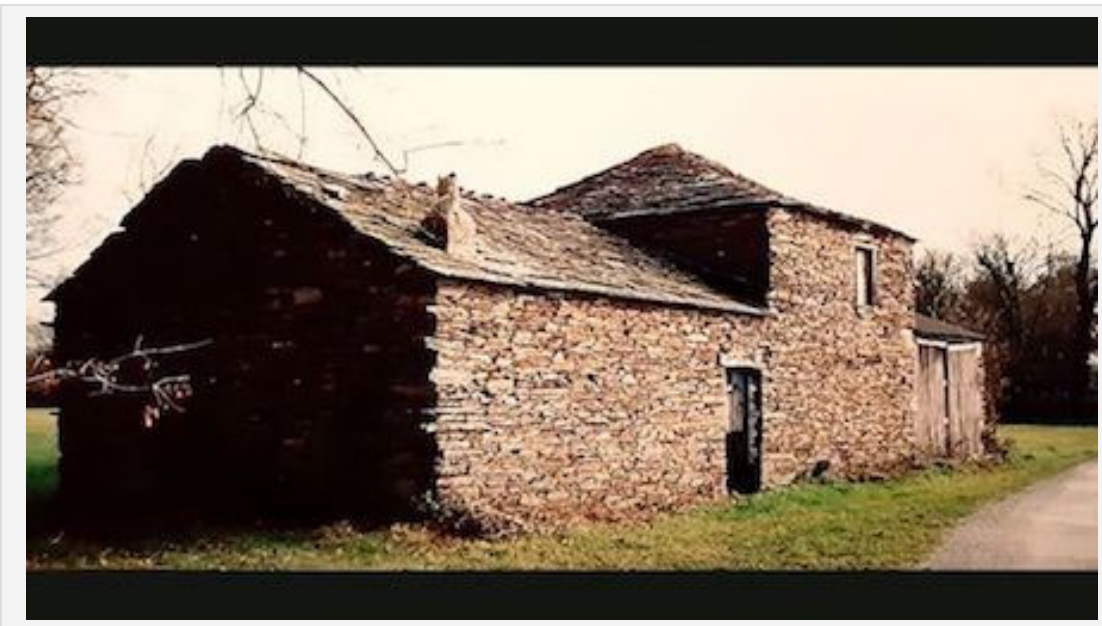

Vivienda-taller en Bonxe construida en el primer tercio del siglo XX.

Curiosamente, el propio hecho de que hasta no hace muchos años la sociedad gallega fuera mayoritariamente rural, dominada por la precariedad y la autarquía económicas propias del período posterior a la Guerra Civil y también del sistema cerrado de la dictadura franquista hasta la llegada de la "apertura" hacia la emigración europea, favoreció que los productos fabricados por los alfareros, al igual que otras artesanías, resultaran imprescindibles para satisfacer las necesidades cotidianas, en cuanto al menaje, de una gran parte de la población - la cual, por otro lado, dio lugar a una gradual estigmatización de la forma de vida de este sector que se encontraba unida al consumo de los productos del barro-. Justamente esto motivó que los útiles fueran durante mucho tiempo los elegidos por el sector numéricamente más amplio de la sociedad gallega. Esto, junto con la necesidad de mantenimiento y continua reposición de estas, permitió que los alfareros alcanzaran la posibilidad de un cierto ascenso social hacia una actividad dotada de mayor prestigio, como era la agricultura vinculada a la posesión de tierra, que funcionaba como marca diferenciadora de estatus en la Galicia rural. Precisamente esta es una de las razones que explica, como ya dijimos, que los alfareros que no habían resuelto su futuro laboral y asegurado sus ingresos fuera del campesinado decidiesen abandonar el oficio o, si se prefiere, reemplazarlo por la actividad agroganadera, mientras que los artesanos que tenían su dedicación principal o complementaria en el sector secundario no tuvieron mayor dificultad para seguir trabajando en el torno.

Las características físicas de las piezas hechas con barro y pertenecientes a esta primera etapa estaban muy en consonancia con la estratificación social de quien las producía, y más aún de quien las consumía, puesto que se trataban en su mayoría de bienes elaborados para la cocina: cacharros domésticos o de almacenaje de alimentos (grano, vino, zorza, etc.). Así, las piezas propias de este primer período productivo eran formalmente sencillas, pensadas para los trajines del uso cotidiano, con escasa o nula ornamentación (que en algunos casos, como el de la decoración cordada (vincos) de Gundivós, poseía una naturaleza polivalente, como refuerzo estructural de la pieza y como añadido ornamental), de tal manera que, aunque hubiera cierta especialización en las mismas, manifestada en la propia nomenclatura de los cacharros (meleiras o chocolateiras) o en la adaptación de las formas para el uso que estaban destinadas, en realidad cualquier pieza podía suplir a otra en un caso de necesidad, de tal manera que no en todas las casas había todas las formas ni tamaños existentes.

Todas estas características son perceptibles a simple vista si observamos las piezas que conforman colecciones públicas o privadas correspondientes a este primer período, en las que se puede apreciar la escasa frecuencia y limitación de los motivos decorativos 0 , simplemente, del vidriado 0 impermeabilización, casi nulo en las piezas más antiguas y, no obstante, mucho más perceptible en algunas pertenecientes a los últimos años de la primera etapa, en la que la ornamentación había ido adquiriendo gradualmente un papel más relevante. Del mismo modo, también se puede constatar el aprovechamiento de una misma forma en distintos tamaños para diferentes usos, como ocurre, por ejemplo, en los casos de las ollas, en función de que estuviesen destinadas a contener leche o vino, o en el caso de las barreñas empleadas para lavar la loza o la ropa, y los barreñós en los que se preparaba y aderezaba la carne de la matanza.

La funcionalidad primordial de las piezas explica, también, que las características más valoradas de las mismas fueran la ligereza y la resistencia, ya que en su uso cotidiano el peso y la fragilidad del material 
con el que se elaboraban eran los obstáculos que todo buen artesano debía solventar para asegurarse, por lo menos mínimamente, el prestigio profesional y la confianza de los compradores. De hecho, durante el proceso de elaboración surgían varios momentos en los que los artesanos demostraban su maestría para asegurar los resultados. Nos referimos, de manera destacada, a la actuación sobre el tipo de materias primas empleadas: dos barros diferentes que reciben, en genérico, los nombres de "barro vivo" y "barro muerto" - aunque, según las zonas, esta denominación puede ofrecer variantes-, designaciones que hacen referencia a las particularidades físicas y químicas de la arcilla que inciden sobre su capacidad de absorción de agua y su plasticidad, de tal manera que con uno sin el otro no se puede trabajar en el torno. En función de que los cacharros fuesen a estar destinados a contener líquidos o a cocinar exigían diferentes proporciones de los dos barros, de manera que si se trataba de buscar la resistencia frente a la acción directa del fuego era preciso preparar la mezcla con una mayor cantidad de barro muerto, incrementada con tierra u otros materiales complementarios, y si el objetivo era el de dotar a la pieza de una mayor porosidad (por ejemplo, para los botijos) de la que se derivara el frescor de los líquidos contenidos, las medidas aplicadas eran invertidas con un incremento en la proporción del barro vivo. Resulta obvio que la capacidad para sopesar las proporciones dependía de un conocimiento preciso, aunque más experiencial que científico.

En segundo lugar, durante el moldeado el artesano demostraba su destreza para subir las paredes con un grosor suficiente para que tuvieran consistencia y pudieran resistir, pero mínimo para aligerar el peso final de los objetos. Los alfareros también mostraban su dominio de la técnica en el proceso de secado, que debía ser gradual y progresivo para evitar la aparición de posibles hendiduras por una deshidratación brusca y finalmente, ya durante la cocción en la que el control de tiempos de duración y temperaturas alcanzadas en los diferentes momentos eran de vital importancia para garantizar que las piezas estuvieran bien cocidas y tuvieran una mayor vida útil.

En la alfarería contemporánea gran parte de esta especialización en la selección, manipulación y elaboración de las materias primas y de los propios objetos se ha perdido, ya que las cualidades de las piezas ya no residen en el formato físico, sino en su representación simbólica. Las piezas pueden ser cocidas en hornos eléctricos; los barros empleados incluyen los refractarios, para aquellas piezas más funcionales, como los asadores o tarteras; los vidriados son abundantes y las decoraciones resultan fundamentales como marcas identificadoras, y, por lo tanto, distintivas de unos lugares concretos. Los tamaños tendieron a reducirse de manera notable o, cuando menos, las piezas con mayor salida en el mercado actual son las que poseen un tamaño pequeño o intermedio, hecho este propiciado, sin duda, por la propia finalidad decorativa que tienen en las casas actuales los objetos realizados con barro.

En el ámbito tradicional, no obstante, el dominio de todos esos factores determinaba la pericia del maestro artesano, mientras que otros miembros de la unidad de producción (familiar o taller) ayudaban en labores complementarias, como era el caso de las desempeñadas por las mujeres, encargadas de suministrar madera como combustible o de ocuparse de la venta de las piezas en los mercados, actividades connotadas como secundarias, pero que, obviamente, son imprescindibles para el mantenimiento del oficio. No obstante, no es casual que la alfarería haya pasado, en buena medida, por la recuperación de la memoria del oficio, manteniendo el papel femenino en las actividades complementarias y centrando el foco de la actividad artesanal en el reducto de masculinidad hegemónica, es decir, en el trabajo que tiene en la elaboración propiamente dicha de las piezas en el torno el centro simbólico (Freire-Paz 2017). Sin embargo, los intentos por recuperar la dedicación efectiva de ciertas mujeres alfareras del pasado (de existencia documentada, si bien cuantitativamente muy minoritarias, a diferencia de lo que ocurre en otros oficios tradicionales claramente feminizados; véase Cabana y Freire-Paz 2021), así como los esfuerzos por fomentar la producción actual también entre las féminas (Cabana y Freire-Paz 2018), otorgándole, por tanto, a esta artesanía, un papel económico y social relacionado con la incorporación de la mujer al mercado de trabajo y con la oferta de ciertas salidas laborales a las mujeres del entorno rural, en consonancia con los tiempos que corren son, a nuestro juicio, una prueba de redistribución de roles determinada por el entorno social actual que no cuadra estrictamente con la noción de "recuperación", lo cual constituye otra muestra evidente del carácter programado y adaptado ideológica y políticamente de la recuperación de la alfarería.

\section{Palimsestos: escribir sobre lo borrado}

La diferenciación cronológica que acabamos de hacer representa no solo una panorámica diacrónica de la historia de la producción alfarera gallega, sino también el sistema de cambios internos o de evolución 
adaptativa de las formas y usos de esta artesanía a los distintos momentos históricos y a las necesidades asociadas a cada uno de ellos. La propia denominación de "tradicional" produce un efecto de agrupamiento que funciona como un factor de cohesión interna entre todas las piezas, ya que lleva implícito el concepto de relevo generacional en la transmisión más allá de los conocimientos, de las formas o de las maneras de hacer asociados a la artesanía del barro. Este referente identitario anclado en la prolongación del pasado hacia el presente y con un carácter continuista hacia el futuro, indisolublemente vinculado con las actividades tradicionales, está en la base de la pervivencia de los oficios relacionados con ellas $\mathrm{y}$, por supuesto, con la alfarería. Sabemos que las identidades se construyen a través de procesos con una cierta querencia por la lentitud, pero en constante elaboración y cambio, y si la producción material de los pueblos se corresponde con una forma particular de adaptación al tiempo y al espacio en el que se desarrollan las culturas, no es de extrañar que los objetos producidos, según una regla pragmática básica, se mantengan en la medida en la que aportan algún valor de uso para el pueblo en cuestión, de tal manera que cuando ya no son útiles, sencillamente dejan de ser producidos. En términos generales, podemos afirmar que existe una cierta tendencia a contraponer las piezas de barro de la etapa antigua y las de la etapa actual por el hecho de que mientras aquellas se utilizaban en la vida cotidiana, estas cumplen solo una función decorativa. Efectivamente, esa diferenciación es cierta, pero precisa, a nuestro juicio, de una explicación más compleja, que afecta a cambios muy notables dentro del mantenimiento de la actividad productiva en la actualidad, llegando incluso a sustentarla. Si la alfarería tradicional gallega pervive hoy, aunque sea de forma residual, en el conjunto de las actividades productivas del país, es porque sus piezas cumplen una función para la sociedad actual que mantiene, precisamente, su valor de uso. Se ha producido una importante variación en cuanto a las funciones desempeñadas por las piezas de barro producidas en Galicia hasta la década de los años sesenta del pasado siglo frente a las que se fabrican hoy en día. Pero, esos cambios en la funcionalidad justifican la aparición de otras características, incluso físicas, en las piezas "de siempre", aunque las imágenes simbólicas que se asocian a la tradición son las que permiten la integración de las novedades en la pervivencia del pasado que representa cualquier objeto de alfarería tradicional elaborado en la actualidad.

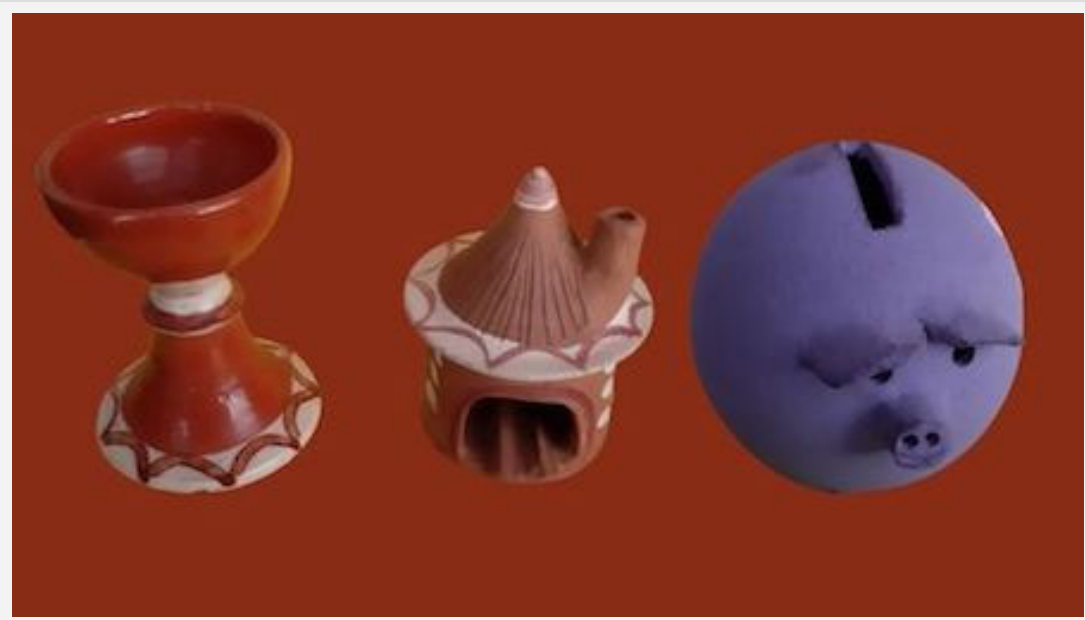

Piezas de alfarería elaboradas en Galicia bajo la denominación tradicional.

Así pues, la alfarería tradicional gallega patrimonializada ejemplifica la transición entre la representación de la cultura material perteneciente al pasado de un pueblo y la pervivencia del oficio en la sociedad actual en dos espectros diferenciados. En uno estaría el mundo institucional que refrenda a través de su estudio, exposición y divulgación la existencia de la alfarería gallega como un referente identitario que ha alcanzado, en los últimos tiempos, y gracias a ese amparo, un espacio propio en la representatividad más elevada de la sociedad gallega, visible en la ocupación de espacios específicos como icono publicitario y de propaganda institucional, cultural, etc., o por su ubicación dentro de los circuitos comerciales oficiales, al pasar a instalarse en emplazamientos específicos dentro de los museos públicos, o por el hecho de haber acaparado un cierto ámbito del mundo comercial, dentro de un sector específico como es el de las artesanías.

Por otra parte, también debemos tener en cuenta el mantenimiento de la actividad en términos tradicionales en el sistema productivo de la sociedad en la que se insertan los artesanos que están haciendo piezas hoy en día en los talleres gallegos. Se puede decir que esta transición se inscribe en un proceso general de selección cultural en el que son visibles algunas de las fases y aspectos 
característicos de esta situación; en concreto, tanto la naturaleza como la historia y la genialidad hacen acto de presencia en este caso. Así, no resulta extraño que la artesanía del barro aparezca asociada, como reclamo de mercado, al llamado ecoturismo o turismo verde, vinculados ambos mediante un proceso de recuperación de formas y relaciones (interpersonales y persona-medio) consideradas típicas de un pasado en el que la sostenibilidad se percibe hoy en día como marca definitoria de dichas relaciones. De este modo, tanto la propia materia prima de la alfarería como el proceso de elaboración en su conjunto responden a la demanda social de respeto a la naturaleza, puesto que los dos se juzgan como inocuos, integrados y plenamente reciclables, encontrando su ubicación ideal en los espacios referenciales rurales o en un entorno urbano simbólicamente connotado con los valores antedichos. No es preciso insistir en la relación de la alfarería con el segundo elemento: la historia, ante la que funciona como objeto lustral, puesto que en la recuperación de la misma ha primado una perspectiva con la que se pretende la ensoñación de un pasado ideal y mítico.

Por último, en el barro, coexisten una dimensión técnica y otra artística, cuando no sagrada. Si su presencia se limitara a las estanterías de los museos aparecería caracterizada como objeto más arqueológico que artístico, puesto que el arte precisa de referentes exteriores que evidencien su continuidad, su capacidad de adaptación, su naturaleza mutable; es decir, el hecho de que aunque técnicamente se puedan limitar e incluso agotar las posibilidades de elaboración de una pieza de barro, la naturaleza artística de esta artesanía impedirá su fosilización, el agotamiento de sus manifestaciones, y garantizará su dinamismo.

\section{El ejercicio del poder: la maquinaria del patrimonio}

Por otra parte, como hemos visto, es posible hablar de una activación de la artesanía del barro por medio de la intervención, tanto en lo ideológico como en lo cultural y en lo económico, de distintas entidades que proyectan sobre el barro la versión identitaria colectiva que ya hemos descrito y que incide en una interpretación política a un tiempo local y regional; por tanto, enmarcada y localizada en el ámbito gallego, si bien equivalente a otros procesos externos a nuestra cultura. 


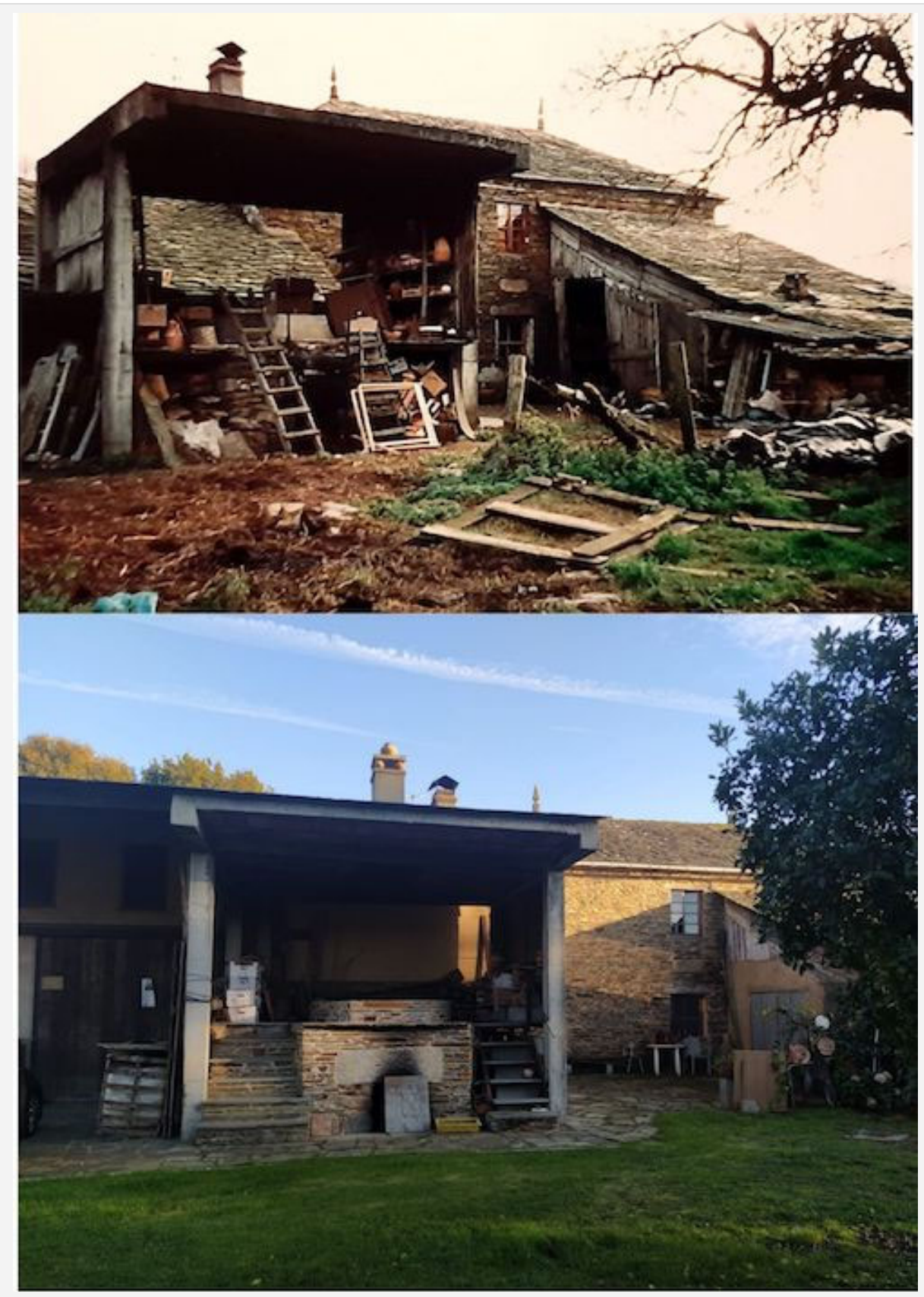

Horno tradicional situado en la parroquia de Bonxe (Outeiro de Rei, Lugo) antes y después de su remodelación propiciada por la Diputación Provincial con fondos europeos (1998/2021).

Cabría identificar, pues, los sujetos que detentan la dirección de ese proceso de recuperación, y que están relacionados con variadas - aunque interactivas - formas del poder, singularmente con el político, pero también con el económico e incluso, como resulta inevitable en la sociedad actual, con el de la información. En el terreno político es preciso introducir ciertas matizaciones, puesto que si bien existe un interés directo en este proceso por parte de las instituciones autonómicas, provinciales y locales. Hay que tener en cuenta actuaciones legislativas, como la Ley de Artesanía de Galicia (1992) o la Ley de Patrimonio Cultural de Galicia (1995), y ejecutivas, como la creación y sostenimiento de una red de centros de artesanía y museos, junto con sus iniciativas, la creación de un Registro General de Artesanía de Galicia o, más actualmente, y con un objetivo al tiempo legal e informativo, la oferta de páginas web específicas, como la de la Consellería de Economía e Industria (http://www.artesaniadegaliciHYPERLINK "http://www.artesaniadegalicia.org/"aHYPERLINK "http://www.artesaniadegalicia.org/".org/). También es cierto que se constata un cierto dirigismo, más o menos visible, hacia estas actuaciones por parte de organismos nacionales o internacionales, como la UE. Dado que el de las artesanías es un sector económico que, al tiempo que se caracteriza, como hemos visto, por un cierto grado de especialización y un reconocimiento social como tal -mayor, obviamente, en la actualidad que en el pasado_, también aparece vinculado al espacio simbólico y físico del medio rural, ha sido objeto de determinadas políticas 
económicas que tratan de aprovechar estas potencialidades. Como es bien sabido, la política económica europea, en lo relativo a Galicia - y, por tanto, los distintos programas sectoriales autonómicos- ha fomentado un progresivo abandono de los sectores productivos relacionados con la ganadería y la agricultura, que pasó de ocupaciones de 570.000 personas en 1976 a 410.000 en 1986, 212.000 en 1996, 129.000 en 2004 u 88.000 en 2009.

Al mismo tiempo, existe la necesidad de tender a fijar la población rural en su medio, para lo cual es preciso ofertarle ciertas posibilidades laborales y económicas - junto con otras, aun menos atendidas-. En este sentido, a la relativa especialización de la alfarería se suma el hecho de no haber desaparecido en su totalidad y de posibilitar, por tanto, un intento de recuperación susceptible de ser disfrazado de reactivación, así como el dato relevante de precisar de una inversión económica baja, debido a la localización de la mano de obra, de las instalaciones para la producción y de las materias primas, además de, en muchos casos, la propia naturaleza artesanal del instrumental necesario. Al mismo tiempo, como ya queda indicado, también la convierten en un sector propicio para proyectar políticas laborales sobre ella, el hecho de encontrarse relacionada tradicionalmente con el medio rural, de ser empleada por lo tanto como factor de asentamiento de la población de este medio, apoyándose al tiempo en la emergencia del subsector turístico ecológico o cultural, y de posibilitar la incorporación al mercado laboral de las mujeres del medio rural. Todos estos condicionamientos, tendentes a personalizar y localizar la artesanía en un medio social, cultural, físico y simbólico concreto pueden resultar de interés si se atiende a las reacciones, económica y mercantil, del público hacia este producto, prestando especial atención a la entrada de artesanías procedentes de países que las insertan en el mercado mundial a precios más asequibles, las resonancias peyorativas relacionadas con un pasado de carencias que la presencia del barro podría despertar en quienes dispongan de memoria individual sobre ellas, la propia competencia con los productos de diseño de origen industrial o las posibles dificultades para integrarla como objeto útil e incluso decorativo en los nuevos hogares e, incluso, sus particularidades para ser empleadas como objetos decorativos.

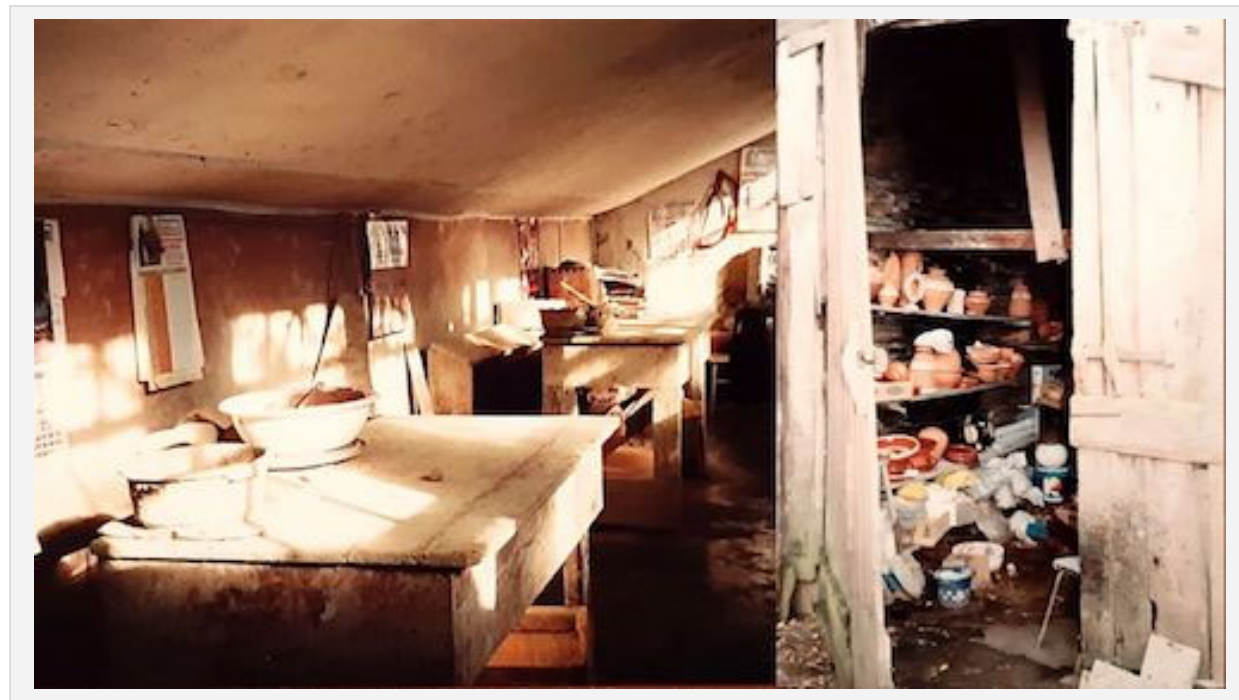

Lugar de producción, almacenamiento y venta de piezas en distintos talleres antes del proceso de puesta en valor acometido a comienzos del siglo XXI. 


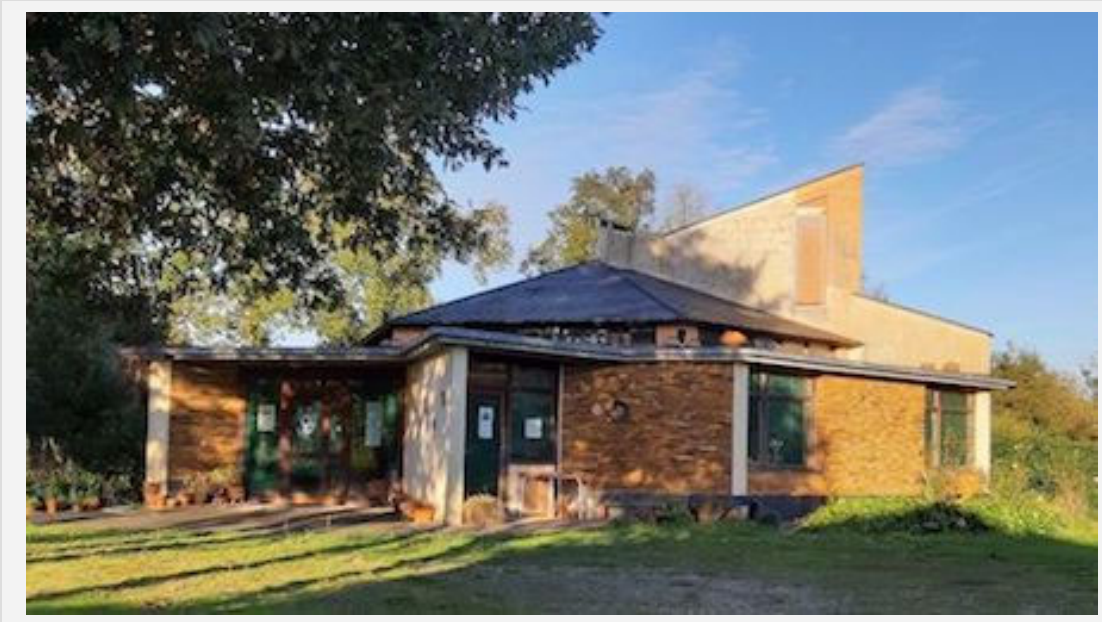

Centro de elaboración, demostración y venta en la actualidad bajo la consideración de la alfarería como patrimonio.

Pero, por otra parte, quizás se podría hablar también de un proceso de selección en otro sentido, según el cual se procedería a establecer un modelo canónico de referencia para la definición del concepto formal, visual y nocional de la alfarería o, para ser más precisos, de los distintos modelos de alfarería fomentados y recuperados. Se trataría de una especie de "normativización" de la artesanía, una creación de un corpus de referencia previo o paralelo al establecimiento del estatus político, legal y cultural que se le pretende dar. Entonces, es preciso que la heterogénea variedad de talleres, técnicas y piezas que existieron en el pasado se conformen en una serie más limitada y, por tanto, accesible, que represente a un tiempo la unidad esencial de la artesanía gallega y su variedad identitaria. Dicha selección, que consiste en la creación de un corpus de referencia moderno fundamentado teóricamente en piezas del pasado, mas no probablemente en un corpus pasado, que no existe, se manifiesta en la priorización de cierto tipo de piezas sobre otras, todas ellas tradicionales, si bien algunas connotadas negativamente por razones socioculturales relacionadas con el pasado, como podría ser el caso de los orinales o de los canecos. También ocurre lo mismo en el caso de la aparición de piezas nuevas, inexistentes en la tradición, o bien en el refuerzo de la producción de piezas otrora minoritarias o casuales, como es el caso de los floreros. En la misma línea de orientación ideológica del artesano, que lo pueden llevar a olvidar unas piezas y a centrarse en la producción de otras, estaría la tendencia a enfatizar ciertos elementos que en el pasado resultaban más secundarios u ocasionales y ahora se convierten casi en motivos centrales, por su capacidad para actuar como evocadores e identificadores del producto entre el público, como es el caso de la decoración o, en general, de las concesiones al aspecto lúdico de las piezas sobre el utilitario.

Tampoco debemos olvidar que otra forma de "normativización" de la artesanía recuperada es la especialización de los talleres o de los alfareros en cierto tipo de piezas, presentadas como representativas de la zona, con el objetivo de reducir la posible competencia entre piezas de distinto origen y de fomentar el hábito de la identificación a partir de ciertos trazos visuales destacados. Así ocurre, por ejemplo, con las ollas de Bonxe, los xarros de Gundivós, los botijos de roscón de Buño o las aceiteras de Niñodaguia. No obstante, en la situación actual también sería posible considerar como sujetos reguladores de la alfarería a los medios académicos y técnicos, puesto que es de ellos de quien depende, al menos en cierta medida, la elección de una versión normativa o de otra, e incluso es posible percibir - sobre todo en el ámbito académico — una pugna por la definición de la noción de identidad que pretende proyectarse, de la pureza o de la esencia que se evoca, así como de los procesos necesarios para ejecutar una recuperación desde el terreno simbólico y cultural hasta el técnico, publicitario, comercial o económico.

En la base del inevitable movimiento de traslación que se ha producido entre la alfarería de la etapa antigua y la que podemos denominar "nueva alfarería tradicional", está el propio carácter funcional de las piezas y de la actividad, incluso más allá de los símbolos materiales que resultan de su ejercicio. Los objetos que en el pasado estaban destinados a contener materias variadas de manera polivalente sirven ahora de contenedores sociales de significados culturales identitarios, en los que la sociedad gallega no solo se ve reflejada, sino que también se percibe como diferenciada en el contexto siempre uniformador de la globalidad. La recuperación de la producción artesanal, así como el interés cultural o patrimonial por las piezas puede ser considerada como uno de los posibles efectos que tiene el refuerzo de las 
identidades locales en la era de la globalización. Ofrece, pues, una respuesta diferente y complementaria a la de la interpretación de la artesanía tradicional como una representación de la autenticidad de una cultura, de corte hasta cierto punto romántico. Este fenómeno postmoderno del recurso a la tradición como principio reactivo o resistente a la uniformización cultural propio de la consideración de la cultura como una red diversa y heterogénea y, al mismo tiempo, como una dinámica en constante elaboración y construcción, no dependiente en exclusiva del recurso al pasado y al museo, funcionaría como una respuesta a la fragmentación o fractalización baudrillariana, al ofrecer una posibilidad de resemantización y reelaboración de lo colectivo en aras de una cultura identitaria: "Esa ficción tan líquida como fracturada, permite tonificar las mercancías transnacionales. Los territorios, esos lugares imaginados, luchan por entrar en los circuitos financieros del capitalismo cognitivo. Y las memorias, esos sueños evocados, se convierten en narrativas imposibles de autenticidad" (Santamarina y Mármol 2020).

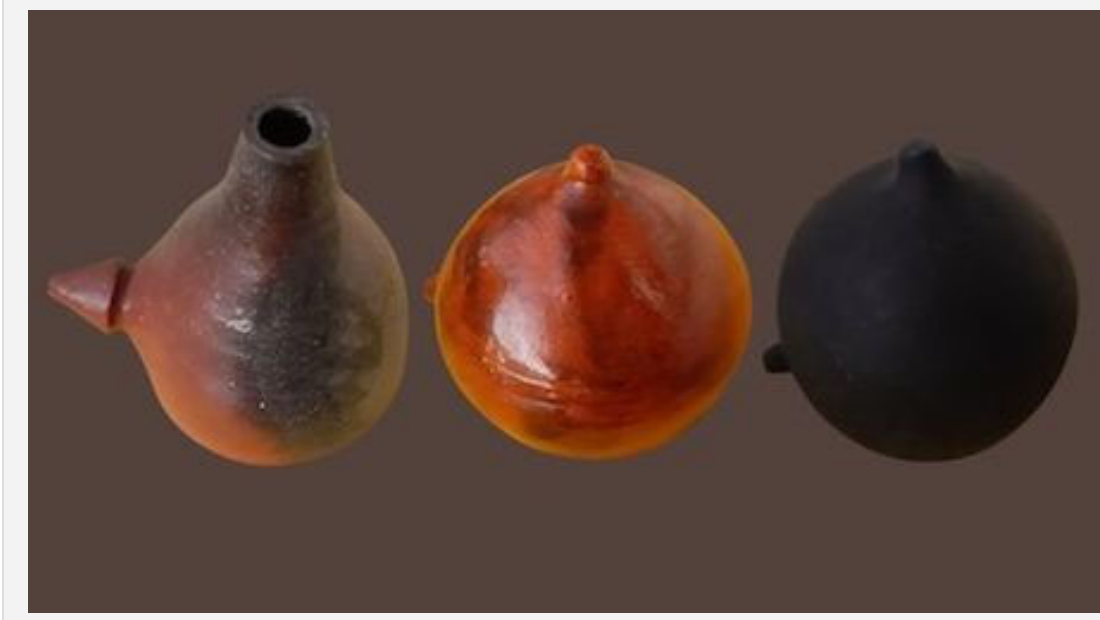

Progresiva asimilación de los rasgos diferenciadores de la alfarería de Gundivós (Lugo) sobre una pezoeira desde la introducción de esta pieza en la zona a comienzos del siglo XXI.

Al mismo tiempo, resulta ser también una respuesta la otra imposición global, en este caso de carácter económico, como es el paso dirigido desde la economía primaria a una terciarización que no ha contado, en cualquier caso, con un proceso industrializador intermedio; en efecto, el relevo de la vinculación rural y de uso pragmático que poseía la alfarería en la etapa tradicional por unas formas de producción y consumo relacionadas con la industria cultural, la mercantilización del patrimonio y los recursos turísticos, dominantes o exclusivos en la actualidad, se encuentra relacionada con la progresiva desarticulación económica agrícola y ganadera del medio rural y con el intento de introducción en el mismo de sistemas económicos alternativos, como ya hemos visto.

\section{Conclusiones: el retorno}

Apuntando a un cierto carácter diferencial de la alfarería respecto de otras artesanías, e insistiendo en un aspecto mencionado de manera dispersa en las páginas precedentes, en relación con el potencial evocador de la artesanía del barro, cabría hacer referencia a su naturaleza intrínsecamente relacionada con el mundo simbólico de la casa. La alfarería es una artesanía localizada, es decir, situada en el espacio preciso de la casa, asociada directamente a los usos y necesidades desarrollados en ella y, en consecuencia, a su simbología, generadora de manera directa de la noción de identidad, de pertenencia, al menos en el ámbito rural tradicional. Probablemente esta localización simbólica espacial es la que permite que la discontinuidad temporal de la artesanía del barro no afecte sustancialmente a su simbolismo inmaterial, cultural, o aun más, que sea precisamente el valor simbólico de lo rural asociado a la vida doméstica lo que perviva en las formas simbólicas actuales del barro. En este sentido, el barro actúa como una prolongación del valor simbólico de la casa, del lugar antes que del espacio, como referente asociado a una identidad suprafamiliar, puesto que incluso los objetos de barro que podían tener un empleo físicamente externo a la casa, se situaban fuera de ella solo de manera transitoria, y siempre en actividades que acababan por evocar y desembocar en el hogar. Pero incluso se puede decir que no existe ninguna artesanía que posea una localización tan central en lo social y en lo simbólico como la de la cocina tradicional, que encierra imágenes reales y metafóricas relacionadas con la 
alimentación (corporal y espiritual), con la elaboración o la conservación del alimento o con la dimensión social de la comensalía. Es en estas coordenadas de un territorio a un tiempo actual y desplazado a un pasado mítico, social e individual, sociocultural y político-económico, pragmático y anti-utilitario, rural y urbano, local y global, tradicional y sostenible, real y simbólico, donde se mueve la artesanía gallega del barro en la actualidad. Las piezas que la componen, alusivas a muy diversas actividades tradicionales, casi siempre desprovistas de todo valor utilitario, conforman un rompecabezas identitario que no siempre posee una razón de ser lógica, pero que apela al pasado y a la identidad como reclamo para justificar nuevas propuestas, la originalidad, la unicidad, la distinción. Al tiempo, los actores responsables de esta presencia de la alfarería en el medio actual son variados y corresponsables de las formas y de los sentidos a ella atribuidos y, entre ellos, a parte de los propios artesanos y de las instituciones políticas, cabe mencionar los museos, los eventos divulgativos y los centros de artesanía. Sobre unas piezas de barro en las que reposa la cultura todo un entramado institucional, normativo y consuetudinario determina su valor social, aquel en el que "convergen el valor económico y el valor simbólico cultural" (García del Hoyo y Jiménez 2015: 127).

Así pues, la alfarería tradicional gallega, cada vez más lejos del pasado, se revela hoy como depositaria del poder que otorga el patrimonio "como instrumento para deseñar o futuro" (Herrero 2021: 12) y que "radica na súa capacidade de articular e cohesionar os grupos en torno a proxectos colectivos, baseándose na importancia emocional que ten para as persoas o pasado e a memoria" (Herrero 2021: 12).

\section{Notas}

Todas las fotografías han sido realizadas por la autora del artículo, Elena Freire Paz.

\section{Bibliografía}

Agudo Torrico, Juan

1999 "Cultura, patrimono etnológico e identidad", Boletín del Instituto Andaluz del Patrimonio Histórico, $\mathrm{n}^{\circ}$ 7 (29): 36-45.

Bustamante Danilo, Javiera

2019 "Rompiendo el silencio. Aportes desde la antropología chilena al campo de estudios de la memoria", Athenea Digital, nº 19 (2): 1-25.

Busto Miramontes, Beatriz

2021 Um país a la gallega. Galiza no NO-DO franquista. Santiago de Compostela, Através Editora.

Cabana Iglesia, Ana (y Elena Freire-Paz)

2018 "Haciendo barro, produciendo género. Mujeres en la alfarería de la Galicia rural desde finales del siglo XX", Arenal: Revista de historia de las mujeres, vol. 25, $\mathrm{n}^{\circ}$ 1: 53-70.https://revistaseug.ugr.es lindex.php/arenal/article/view/5635.

2021 "Vendedoras de barro. Mujeres rurales y los límites de 'lo doméstico' a mediados del siglo XX", en Teresa M $\mathrm{M}^{\mathrm{a}}$ Ortega y Ana Cabana, "'Haberlas, haylas'. Campesinas en la historia de España en el siglo XX. Barcelona, Marcial Pons: 157-186.

\section{Carrera Díaz, Gema}

2019 "Participación social, patrimonialización 'expandida' y nuevos sujetos patrimoniales", en Cristina Sánchez-Carretero y otros (ed.), El imperativo de la participación en la gestión patrimonial. Madrid, CSIC: 217-237.

Davallon, Jean

2014 "El juego de la patrimonialización”, en Xavier Roigé y otros (ed.), Construyendo el patrimonio cultural y natural Parques, museos y patrimonio rural. Valencia, Editorial Germania/AVA: 47-76. 
2004 La recuperación de la alfarería tradicional en la provincia de Lugo: procesos socio-económicos y culturales. Santiago de Compostela, Servizo de Publicacións USC.

2017 "Estereotipos de barro: mulleres na olería tradicional galega", Boletín galego de literatura, $\mathrm{n}^{\circ} 50$, 115-137.

file://C:/Users/usuario/Downloads/3985-Texto\%20do\%20artigo-20578-1-10-20170614.pdf.

Estrada i Bonell, Ferrán (y Camila del Mármol Cartañá)

2014 "La patrimonialización de la cultura inmaterial: Ios oficios", Arxius de Sociología, n 30: 45-58.

García Alén, Luciano

1983 La alfarería de Galicia. A Coruña, Barrié de la Maza, 2020.

García Canclini, Néstor

1999 "Los usos sociales del patrimonio cultural", en Encarnación Aguilar (coord.), Patrimonio etnológico. Nuevas perspectivas de estudio. Granada, Comares: 16-33.

García del Hoyo, Juan José (y Celeste Jiménez de Madariaga)

2015 "Teorías del valor: coincidencias y divergencias en la economía y la antropología social”, Revista de Economía Institucional, vol. 17, $\mathrm{n}^{\circ}$ 33: 109-131.

Hafstein, Valdimar

2012 "Cultural Heritage", en Regina F. Bendix y Galik Hasan-Rokem (ed.), A Companion to Folklore. Oxford, Wiley Blackwell: 500-519.

Herrero Pérez, Nieves

2011 "La posmodernización de la tradición. Nuevos retos para la gestión del patrimonio", Revista de Antropología Social (Madrid), vol. 20: 293-307.

2021 "Un enfoque crítico do patrimonio cultural", Tempos Novos, n² 291: 12-14.

Jiménez de Madariaga, Celeste

2019 "El turismo patrimonial: la cultura 'en venta'”, en Juan Antonio Márquez Domínguez y Jorge Llamas Chávez (dir.), Hélices y anclas para el desarrollo local. Universidad de Cartagena/Universidad de Huelva: 803-812.

Marcos Arévalo, Javier

2010 "El patrimonio como representación colectiva. La intangibilidad de los bienes culturales", Gazeta de Antropología, $\mathrm{n}^{\circ} 26$ (1), artículo 19.

https://digibug.ugr.es/handle/10481/6799.

Quintero Morón, Victoria (y Cristina Sánchez-Carretero)

2017 "Los verbos de la participación social y sus conjugadores: contradicciones de un patrimonio 'democratizador', Revista Andaluza de Antropología, n 12: 48-69.

Rei, Mariana

2016 Do operário ao artista. Uma etnografia em contexto industrial no Vale do Ave. Porto, Deriva das Palavras-Monde Diplomatique.

Rivera Andía, Juan Javier

2012 Reseña del libro: Luis Díaz y Pedro Tomé (coord.), La tradición como reclamo. Antropología en Castilla y León (Salamanca, Junta de Castilla-León, Consejería de Cultura y Turismo, 2007), Gazeta de Antropología, $\mathrm{n}^{\circ} 28$ (2).

Santamarina, Beatriz (y Camila del Mármol Cartañá)

2020 "Para algo que era nuestro... Ahora es de toda la humanidad': el patrimonio mundial como expresión de conflictos", Chungará, nº 52 (1): 161-173.

Seseña Díez, Natacha

1997 Cacharrería popular: la alfarería de basto en España. Madrid, Alianza Editorial.

Smith, Laurajane

2011 “El 'espejo patrimonial'. ¿llusión narcisista o reflexiones múltiples?”, Antípoda. Revista de 
Antropología y Arqueología, nº 12: 39-63.

Velasco Maíllo, Honorio M.

2012 "De patrimonios culturales y sus categorías", Gazeta de Antropología, nº 28 (3), artículo 13.

http://www.gazeta-antropologia.es/?p=4066. 